\section{Embedding Education for Sustainability (EfS) into Teacher Education in the South Pacific, Challenges and Opportunities}

Lynley Tulloch

The University of the South Pacific, Suva, Fiji

\section{Introduction}

Within the context of neoliberal global capitalist development, economic growth has led to the overstepping of planetary boundaries (PB). Scientists have warned that there are environmental limits within which humanity and nonhuman life can safely operate and that, if we exploit these, the consequences will be bleak. Climate change and biodiversity integrity are two of the core PBs whose fundamental importance to the maintenance of the Earth system is now an area of key concern. They cause irreversible damage to ecosystems and threaten the very conditions that make life on Earth possible.

Other environmental issues include reduction of the ozone layer, air and water pollution, desertification, and toxic waste. Such drastic environmental issues have profound effects - including food insecurity, poverty, loss of livelihoods, and alienation of indigenous peoples from their lands - that are unequally felt on a global scale. In the Pacific Island region, climate change is responsible for an increasing number of extreme weather events, rising sea levels, and an increase in disease and ill-health.

Education for Sustainable Development (EfSD) has emerged as an important tool for implementing the kind of social change necessary for moving forward sustainably. Yet the discourse of sustainable development (SD) is largely based on western worldviews and global developmental agendas. Most notably the dominant version of United Nations (UN)-led SD is underpinned by the assumptions of free- market neoliberal capitalism. This raises questions about its adequacy as a framework to use in the context of Pacific Island nations (PINs), a region that has a unique set of sustainability issues due to its reliance on local ecosystems for subsistence and small land area coupled with a high population density (Kim et al. 2015).

There are many challenges and opportunities for teacher educators in Pacific Island nations in embedding EfSD in teacher education programs. PINs are culturally diverse and yet face a common set of sustainability issues that threaten their future. This chapter points out that the discourse of UN-led SD needs to be deconstructed and theorized by teacher educators in accordance with Pacific Island ways of knowing and being. It also establishes the need for professional development for teacher educators in developing meaningful, relevant, and empowering spaces for sustainability education. 


\section{Sustainable Development}

The discourse of SD is focused on the ongoing development of the kind that takes ecological limits into account so that sufficient resources and a habitable Earth are available to sustain future generations. Originally, the idea of SD derived from ecological politics and antiglobalization Third World politics in the 1970s. Key ideas such as "carrying capacity," "limits to growth," and "finite resources" were generated by early environmental authors to convey that economic growth and "first world" development were stressing the Earth's ability to regulate itself. These ideas have, since the 1980s, been captured by the United Nations and subordinated to the interests of free-market global capitalism (Tulloch 2017). The dominant SD discourse is now embedded in nearly every domain of policy. This has been the result of global UN mandates that have been disseminated to various local contexts including the Pacific Island region.

SD is thus not a value-free concept and supports a range of assumptions about the environment, social organization, and economy. The environment is primarily conceived of from within a rational-scientific-technological western framework, with its focus on the utilitarian value of nature as a both an economic resource and lifesupport system for humanity. These ideologies form a position which is a good fit with the logic of capitalism and industrialization. The dominant version of SD operates within, and indeed supports, the rationality of global capitalist growth. In addition, SD supports an anthropocentric orientation and has a "problem solving, soft-green managerialist/technological approach to the environment" (Tulloch 2017).

The dominant version of SD that is encapsulated in the UN favors the context of the free market for reform. Free markets are regarded as a driving innovation and creating the kind of technological and social change necessary for a green capitalist society that functions within planetary limits. This is a very problematic discourse in Pacific Island contexts, with their highly diverse and significant ecologies and cultures. Pacific Island peoples have lived sustainably with the land and sea for thousands of years. The imposition of globalization and market-based neoliberal logic threatens to erode the wisdom and interconnectedness Pacific Island peoples have with their environments. It is essential that teacher educators recognize this and challenge the Eurocentric nature at the heart of SD.

\section{Education for Sustainable Development}

Education for Sustainable Development is a United Nations-led initiative aimed at developing a global populace with the competencies to work toward a peaceful, inclusive, and ecologically stable future. It is a discourse that has emerged especially since the 1990s. The formal establishment of the concept of EfSD occurred at the Rio de Janeiro United Nations' Conference on Environment and Development. The intent and substance of EfSD are based on three important historical global documents - the Belgrade Charter, the Tbilisi Declaration, and Agenda 21. These global initiatives called for EfSD to be embedded in policy and curricula in formal and non-formal education sectors, including public schooling from early childhood education to higher education. Many PINs are signatories to the document arising from the 1992 Rio Earth Summit - Agenda 21. A commitment to EfSD is evident in virtually all aspects of Agenda 21.

The UN Decade of Education for Sustainable Development (DESD 2005-2014) has been another significant global tool to promote EfSD. The launching of the DESD resulted in new developments in the Pacific Island region. These include the Pacific Education for Development Framework and its Action Plan for Sustainable Development in the Pacific Islands (2008-2014) (Corcoran 2010). This document identifies formal education and training as one of the priority areas, with teacher training established as an area of significance.

EfSD can be broadly located in the field of citizenship education and espouses what are often considered universal values and concepts. However, it is important to stress that they are predominantly based on western values and 
worldviews. The goal of the dominant UN-led version of EfSD is to develop competencies in youth to make good democratic decisions about sustainability issues based on active inquiry and problem-solving. The focus is on developing future environmentally aware citizens with appropriate knowledge, attitudes, values, and skills to work toward a sustainable future.

The dissemination of this model of SD and EfSD to PINs can be considered as a continuation of colonialism. However, and somewhat paradoxically, the model also contains spaces for resistance that align with the original radical version of sustainability. SD acknowledges and emphasizes social justice and the creation of democratic spaces to include indigenous voices. It appreciates the interconnectivity between people and their environments.

In addition EfSD is progressive in that it supports a holistic and integrated approach to learning and teaching that engages students in contextual and relevant learning opportunities. EfSD supports the idea of students learning within the context of their communities, engaging in relevant issue-based exploration of key sustainability issues that affect them. EfSD is also based on values exploration, and for educators in PINs, this is significant because it allows a reframing of responses to sustainability issues in terms of Pacific Island value systems. Moreover, EfSD supports learner participation and action and is thus transformative in nature and intent. The focus on the importance of indigenous knowledge systems, coupled with a transformative approach to education, creates possibilities for teacher educators from PINs to reframe sustainable development in terms of Pacific Island values, epistemologies, and ontologies.

It is important that this challenge be implemented by supporting teacher educators with professional development opportunities. EfSD is a specialized field and requires a deep knowledge about sustainability issues by the teacher. Teacher educators also need to understand what approaches are generally used in EfSD and the critical importance of these to its success. Finally, professional development in decolonization and Pacific studies will support teacher educators in ensuring that EfSD is relevant, critical, and meaningful. These qualities are all hallmarks of EfSD.

\section{Sustainable Development in Pacific Island Contexts}

The Pacific Ocean is of high significance for the sustainability of the Earth. It is an active carbon sink and supports a wide biodiversity of flora and fauna. It is home to a diverse range of indigenous peoples and their cultures and languages. Recognition of PINs as a special sustainability case is embedded in most international sustainability agreements, which most Pacific Islands are active partners of and signatories to (Corcoran 2010).

For PINs, climate change is undoubtedly the biggest sustainability issue they face. By the end of this century, sea levels will rise by $1 \mathrm{~m}$. Lowlying island nations including the Marshall Islands, Tuvalu, and Kiribati will very likely become uninhabitable (Kim et al. 2015). This poses a direct threat to the sustainability of the unique cultures, languages, and identities of the people who are indigenous to these islands. The health and well-being of Pacific Island people are also threatened. "[A]pproximately 250000 additional deaths are projected to occur every year from malnutrition, malaria, diarrhea and heat stress attributable to climate change" (Kim et al. 2015).

The increase in extreme weather events such as cyclones as a result of climate change is another serious issue for Pacific Island people. Many Pacific Island peoples live close to the reef and draw on it for their sustenance and livelihoods. However, cyclones cause damage to coral reefs and marine life. Coral reefs are important natural breakwaters and support marine life. The damage to coral reefs caused by climate change implicates both environmental and social sustainability. Cyclones also damage crops and housing, leaving people vulnerable to food insecurity and lack of shelter. It is clear that issues of environmental sustainability are closely tied to social justice concerns. 
In addition to these concerns, many PINs are struggling with issues associated with global economic development, including the breakdown of sustainable traditional production alongside unsustainable export of fishery and forestry products. Another issue is the dependency of PINs on imported food which is causing a rise in nutritionrelated, noncommunicable conditions such as heart disease and diabetes. Other social sustainability issues in PINs include a rise in social and political restlessness and crime (Helu Thaman 2010). The issues are complex and interrelated. Alongside health and security issues, Pacific Island youth are also having to deal with the loss of their cultural, economic, and linguistic traditions.

\section{Teacher Education for Sustainable Development in Pacific Island Contexts}

Currently, "most Pacific governments and foreign aid organizations ... agree that teacher education is vital for the success of curriculum reform and the promotion of sustainable development in our region" (Helu Thaman and Thaman 2009, p. 67). Teacher educators in universities are ideally situated to answer the global call for SD. Our future teachers are at the foreground of supporting young people to become ecologically aware and knowledgeable of the sustainability issues that threaten their future. Students can experience a socially transformative education that empowers them to participate meaningfully in future ecological and social change.

However, embedding EfSD in teacher education comes with challenges. The concept of SD is complex and has been subject to intense contestation both within and outside academia. Helu Thaman and Thaman (2009) argue that globalization has many worrying trends including the "pressure on island governments to adopt imported development and educational strategies associated with the overseas development aid and market imperative" (p. 68). As discussed above, the UN-led initiatives are based on free-market capitalist ideologies, which are alien to Pacific Island ways of being.
The challenge for teacher educators in the Pacific region is to enter this debate and deconstruct the western model of sustainable development. EfSD programs in teacher education can then be reconceptualized in terms of Pacific Island knowledge systems, spiritualities, languages, and values. UN-led initiatives offer spaces of possibility for developing a culturally relevant teacher education program in EfSD in Pacific Island nations. The concept of education as "social transformation" was stated in principle one of Agenda 21. This opens up the possibility of a socially transformative education that is based on the voices, experiences, narratives, values, and pedagogies of people from PINs.

The social dimension of sustainability calls for a focus on equity and peace and celebrates diversity and the importance of indigenous knowledges. Within the social realm, education is considered an influential way to shift people's attitudes, beliefs, and behaviors toward a sustainable future. Social sustainability also holds consideration for future generations - and this is a significant theme given the aforementioned serious issues faced by PINs.

However, as discussed above, it is important that EfSD is embedded in local contexts and offers genuine opportunities for deconstruction and critique. Embedding EfSD in teacher education programs in the Pacific Island region requires a strong commitment to understanding the significance of the social sustainability pillar, in which sustainability is about cultural survival and continuity. Within this pillar, island cultures need to be woven through more than just the course content they need to be an intricate part of the pedagogical, epistemological, and ontological commitments of teacher education programs. These need to be integrated throughout the various learning areas taught in teacher education programs. Teacher education programs can embed sustainability learning throughout social science, the arts, language, physical education, and technology. For example, the use of traditional ecological knowledge can be embedded in science learning.

An exploration of Pacific Island values and ways of being can be included in social science learning. Asking teacher education students to 
reflect on core concepts from their Pacific Island contexts and think of how they relate to sustainability concepts offers profound opportunities for a more transformative education. Teacher educators can engage students in values exploration through reflecting on and exploring values that are considered central to Pacific Island ways of being. Corcoran (2010, p. 130) argues that although Pacific Island peoples' cultures are diverse, there are some common values and practices:

\begin{abstract}
The predominant values are trust, deep respect for elders, creativity, restraint, reciprocity, compassion, awareness of interdependence with the environment, and an abiding faith in God .... and there is a deep spirit of heritage that includes intense consciousness of land and sea. It embraces and permeates all that we do there, all that we know, all that we are.
\end{abstract}

The interlinking of environmental, social, and economic concerns is the foundation for authentic and culturally responsive teacher education. Teacher educators should reflect on the need for young people from the Pacific Islands to lead sustainable lives. This includes reflecting on the significance of cultural values and lifestyles and associated knowledge that has enabled Pacific Island peoples to live sustainably for many generations.

Through reconceptualizing key sustainability concepts and linking them to Pacific Island contexts, educators can work toward making learning meaningful and responsive (Helu Thaman 2010). One such concept is that of peace. Helu Thaman (2010, p. 354) posits that in the context of PINs:

\footnotetext{
... peace is something that is the outward expression of appropriate interpersonal and inter-group relationships, known in Polynesian societies as vaa/wah. Today positive vaa or its equivalent, is often seen as a pre-condition to peaceful co-existence and sustainable development ...
}

Within Pacific Island contexts, it is also important that educators should prioritize the significance of "relationships" between people and between people and the environment. Relationships in Pacific Island contexts frame responsibilities and community identity. They need to be foregrounded in teacher education as they are central to the collective good will and peace (Helu Thaman 2010).

Another challenge for teacher educators embedding EfSD in teacher education in PINs is the sheer scale and scope of economic, social, and ecological sustainability issues. These involve not only economic and political instability and ecological problems (as discussed above) but also alienation of many youth in the Pacific Island region from their own cultural roots.

The insidious encroachment of globalization and its expression in schooling systems in PINs have further impacted this. A narrow technicist approach to the curriculum, coupled with rote memorization and external examinations, sometimes predominates in classrooms in PINs. This does not allow for the kind of complex, studentcentered, holistic, and integrated learning favored by EfSD. Using the culturally responsive and transformative pedagogies that are at the heart of EfSD theories will enable a more genuine and empowering engagement by students. Teacher educators can model these pedagogies which are student-centered and engage higher-order thinking skills such as critical reflection.

\section{Conclusion}

Sustainable development is a discourse that is underpinned by western worldviews, although it includes spaces for the expression of indigenous knowledge. One challenge for teacher educators in the Pacific Island region is to deconstruct the westernized ideologies and values that inform EfSD UN-led initiatives. This leads to opportunities to deconstruct and reconceptualize core sustainability concepts from the point of view of Pacific Island values and knowledge systems. This chapter has supported an alternative, more genuine approach to EfSD in PINs that challenges the imposition of western worldviews. It also establishes the need to embed an education that is more sustainable to the development of Pacific Island teachers in the Pacific Island region. 


\section{References}

Corcoran, P. B. (2010). The Pacific way: Sustainability in higher education in the South Pacific Island nations. International Journal of Sustainabiliy in Higher Education, 11(2), 130-140. https://doi.org/10.1108/ 14676371011031856.

Helu Thaman, K. (2010). Teacher capacities for working towards peace and sustainable development. International Journal of Sustainability in Higher Education, 11(4), 353-364. https://doi.org/10.1108/ 14676371011077577.
Helu Thaman, K., \& Thaman, R. (2009). Pacific Island principles: Learning to live wise and sustainable lives. In P. Corcoran \& P. Osano (Eds.), Young people, education, and sustainable development (pp. 63-75). The Netherlands: Wageningen Academic Publishers.

Kim, R., Costello, A., \& Campbell-Lendrum, D. (2015). Climate change and health in Pacific island states. Bulletin of the World Health Organization., 93, 819.

Tulloch, L. (2017). The transnational state, neoliberalism and environmental education policy: A New Zealand case study. Contemporary Readings in Law and Social Justice, 8(2), 170-195. 